\title{
Creating Head Space: Using Spaced Retrieval Practice to Teach Cranial Nerves to Graduate SLP Students
}

\author{
Rachel K. Johnson \\ Old Dominion University, r1johnson@odu.edu \\ Anne Michalek \\ Old Dominion University, aperrott@odu.edu \\ Corrin Richels \\ Old Dominion University, crichels@odu.edu \\ DOI: https://doi.org/10.30707/TLCSD3.2Johnson
}

Follow this and additional works at: https://ir.library.illinoisstate.edu/tlcsd

Part of the Speech Pathology and Audiology Commons

\author{
Recommended Citation \\ Johnson, Rachel K.; Michalek, Anne; and Richels, Corrin (2019) "Creating Head Space: Using Spaced \\ Retrieval Practice to Teach Cranial Nerves to Graduate SLP Students," Teaching and Learning in \\ Communication Sciences \& Disorders: Vol. 3: Iss. 2, Article 7. \\ DOI: https://doi.org/10.30707/TLCSD3.2Johnson \\ Available at: https://ir.library.illinoisstate.edu/tlcsd/vol3/iss2/7
}

This Scholarship of Teaching and Learning Research is brought to you for free and open access by ISU ReD: Research and eData. It has been accepted for inclusion in Teaching and Learning in Communication Sciences \& Disorders by an authorized editor of ISU ReD: Research and eData. For more information, please contact ISUReD@ilstu.edu. 


\title{
Creating Head Space: Using Spaced Retrieval Practice to Teach Cranial Nerves to Graduate SLP Students
}

\author{
Abstract \\ The purpose of this study was to investigate the effectiveness of spaced retrieval practice on graduate \\ speech-language pathology (SLP) student's long-term retention of cranial nerves. This is a quasi- \\ experimental design study using a repeated measures and between group design where the control group \\ was not randomly assigned. The accuracy and quality of cranial nerve knowledge was measured in \\ graduate SLP students who did not practice spaced retrieval (control), and those who practiced spaced \\ retrieval for three (EG1) or four (EG2) semesters. The quality and accuracy of cranial nerve knowledge \\ improved significantly for both experimental groups compared to the control group. When controlling for \\ accuracy from typical instruction, a significant difference in accurate recall did not occur for either \\ experimental group until the third semester with continued significant improvement for EG2 in the fourth \\ semester. The difference in the quality of recall between the first and last semester was significant for \\ EG2 only. These results confirm that participating in spaced retrieval practice one time is inadequate for \\ long-term retention. The findings reassure SLP educators that infusing spaced retrieval practice into \\ content rich courses will have a positive impact on graduate SLP student's retention.
}

\section{Keywords}

spaced retrieval practice, long-term retention, spaced repetition, student learning, cranial nerves

\section{Cover Page Footnote}

We would like to extend our appreciation to Melissa Gies for her assistance with this study. 
Post-secondary educators are challenged to implement high impact practices that facilitate longterm learning. The consequences of failed student learning could be as innocuous as generating the perception that the student has wasted their time and money on a meaningless class or could be as profound as impacting the student's ability to critically problem solve in a discipline-related context. For graduate speech-language pathology (SLP) students, long-term retention of new learning is imperative to build the needed knowledge and skills for clinical practice. For educators, it is essential to understand the impact that evidence-based instruction methods have on graduate SLP students' long-term retention of content related material.

The American Speech-Language-Hearing Association (ASHA) standards for the Certificate of Clinical Competence in Speech-Language Pathology require that students demonstrate knowledge of basic human communication and swallowing processes (Council of Clinical Certification in Audiology and Speech-Language Pathology of the American Speech-Language-Hearing Association, 2013). Retention and confidence of anatomy and neuroanatomy knowledge is reported as poor, despite its application across the lifespan for communication and swallowing processes in all clinical settings (Dickson \& Stephens, 2015; Martin, Bessell, \& Scholten, 2014). Professionals relate the limited retention of neuroanatomy to the blocked schedule of instruction and lack of revisiting the material throughout the graduate curriculum (Martin et al., 2014). This highlights the importance for educators to expand reflection of their pedagogy practice to include the evaluation of student learning and long-term retention as described in the scholarship of teaching and learning in SLP (Dalton, Klein, \& Botts, 2017). Initiatives have begun to revise pedagogy practice in communication science disorders from a theory first to a practice first model (Brackenbury, Folkins, \& Ginsberg, 2014; Folkins, 2016). Several curriculum redesigns integrating theory and practice have been reported including problem-based learning, simulation models, and horizontal and vertical integration (Dudding \& Nottingham, 2017; Strobel \& van Barneveld, 2009; Vinney \& Harvey, 2017). Initial studies have reported positive student outcomes; however, the downside to these approaches is they can be costly (time and money), can take several years to integrate into the curriculum comprehensively, and can require long-term application before any benefits are seen.

An alternative approach to improve student learning and long-term outcomes is to reconsider how learning happens. Retrieval based learning has been shown to be an effective technique to enhance learning, retention, and transfer of knowledge across multiple tasks, ages, and ability levels (Karpicke, 2017). Evidence indicates that spaced retrieval practice not only improves long-term retention and recall (Dunlosky, Rawson, Marsh, Nathan, \& Willingham, 2013; Halamish \& Bjork, 2011; Roediger \& Karpicke, 2006; Roediger \& Pyc, 2012), but also promotes flexible use and transfer of learned content (Carpenter, 2012; Roediger \& Butler, 2011). In addition, when spaced retrieval is completed as a low stakes or no-stakes test, it improves metacognitive monitoring (accurately knowing what you do not know), decreases mind wandering, and reduces testing anxiety (Agarwal, D'Antonio, Roediger, McDermott, \& McDaniel, 2014; Soderstrom \& Bjork, 2015). Spaced retrieval practice has been shown as a valid and reliable teaching strategy for a variety of learners with reported positive outcomes when used as a teaching strategy in primary and secondary education (Baturay, Yildirim, \& Daloglu, 2009; Dobson, 2013; Metcalfe, Kornell, \& Finn, 2009; Sobel, Cepeda, \& Kapler, 2011). Positive outcomes have also been reported for learning a new motor skill in a healthy population (Shea, Lai, Black, \& Park, 2000) and as a strategy to facilitate functional memory and naming skills in persons with progressive or acquired neurogenic disorders (Brush \& Camp, 1998; Middleton, Schwartz, Rawson, Traut, \& Verkuilen, 
2016). Although spaced retrieval practice is an evidenced-based rehabilitation technique used by SLPs, it has not been studied as a technique to enhance long-term retention of neuroanatomy in SLP graduate students.

The effectiveness of spaced retrieval practice is secondary to the strengthened connections between networks of related information that occur with each episode of forgetting and effortful retrieval of prior knowledge (Larsen, 2018). The attaching of new concepts to prior knowledge enables learners to better encode the new information by elaborating on existing concepts (Grimaldi \& Karpicke, 2012; Huelser \& Metcalfe, 2012). Thus, the purposeful recall of to-beremembered content generated by spacing a series of testing tasks produces large effects of learning (Weinstein, Madan, \& Sumeracki, 2018). There is strong evidence in support of spaced versus no spaced retrieval practice in healthy learning across the age span (Carpenter, Cepeda, Rohrer, Kang, \& Pashler, 2012; Greene, 2008; Karpicke \& Bauernschmidt, 2011). Uncertainty remains on the optimal conditions and schedule to maximize the benefit such as the length of time between spaced trials (Karpicke \& Bauernschmidt, 2011; Logan \& Balota, 2008; Logan, Castel, Haber, \& Viehman, 2012), task difficulty (e.g., multiple-choice, free-recall) (Carpenter \& DeLosh, 2006; Pyc \& Rawson, 2009), and feedback on accuracy of spaced retrieval practice (Roediger \& Butler, 2011). Feedback is not necessary, but can amplify retention as long as an attempt at retrieval has been made (Butler, Karpicke, \& Roediger, 2008). This can be particularly beneficial to facilitate metacognitive monitoring and ensure benefit when tasks with a high level of difficulty are completed with minimal success (Butler, Karpicke, \& Roediger, 2007; Rowland, 2014). Given the breadth of knowledge graduate SLP students are expected to learn in two years, it is essential that with each class they build on prior knowledge. Cranial nerves are one example of knowledge graduate SLP students are required to recall and elaborate on as they learn about new disorders. Consequently, we chose cranial nerve knowledge as our variable because that knowledge spans across coursework, semesters, and content. The strong evidence for spaced retrieval practice, along with its versatility to adapt according to the task demand, make it an ideal teaching strategy for long-term retention of cranial nerves in graduate SLP students.

The purpose of this study was to investigate the effectiveness of spaced retrieval practice on graduate SLP students' long-term retention of cranial nerves. While there is research seeking to understand how best to present cranial nerve content (Dickson \& Stephens, 2015; Lone et al., 2018; Richardson-Hatcher, Hazzard, \& Ramirez-Yanez, 2014), there is a paucity of data regarding effects of instructional methods on the long-term retention of cranial nerve knowledge, especially in SLP students. Cranial nerve knowledge was chosen due to its importance for clinical skills (Martin et al., 2014), its application across the lifespan for communication and swallowing processes (Carnaby, 2016), and the lack of long-term retention demonstrated by the graduate students enrolled in our program. By completing a project focusing on practice frequency of spaced retrieval practice for improved retention of cranial nerves, this study addresses our student learning concerns and fills a crucial gap in the literature. Unlike other approaches to enhance student learning outcomes such as problem-based learning (Strobel \& van Barneveld, 2009) or horizontal integration (Vinney \& Harvey, 2017), there is no need for curriculum changes or adaption of pedagogical framework to fit a model of learning. The results will extend SLP educators' knowledge and potentially improve their teaching practices by confirming a versatile, functional, and empirically supported teaching strategy that could be applied to a number of topics (i.e., speech science, language). The primary aim of this project was to measure cranial nerve knowledge in 
graduate SLP students while manipulating the frequency of spaced retrieval practice. The following specific research questions guided our inquiry:

1) Do SLP graduate students who participate in spaced retrieval practice have better retention of cranial nerve knowledge (e.g., name, type, function, body part innervated) as measured by accuracy and quality of responses than students who did not participate in spaced retrieval practice?

2) Does the accuracy and quality of cranial nerve knowledge (e.g., name, type, function, body part innervated) recalled depend on the number of semesters the graduate SLP students participated in spaced retrieval practice?

\section{Methods}

This study was approved by the university human subjects Institutional Review Board. Students were assigned a numeric code to remove all identifying information and allow tracking of changes in performance from semester to semester. All data collected were anonymous and independent of course grades.

Participants. Graduate students enrolled in a SLP master's degree program were recruited to voluntarily participate in this study $(N=48)$. The SLP master's program requires a minimum of 42 credit hours of coursework and 15 hours of clinical work. The program takes either five or six semesters to complete depending on which semester students begin clinical work. All students were enrolled in courses which used a traditional face-to-face format. The study took place over the course of four consecutive semesters beginning in Spring, 2017 and concluding with the last data collection in Spring, 2018.

Table 1. Typical curriculum, clinic rotation schedule, and spaced retrieval practice for each participant group.

\begin{tabular}{|c|c|c|c|c|c|c|c|c|c|}
\hline \multirow{2}{*}{$\mathbf{S}$} & \multirow{2}{*}{$\begin{array}{c}\text { Cranial nerves } \\
\text { in a TYPICAL } \\
\text { curriculum } \\
\text { coursework }\end{array}$} & \multicolumn{5}{|c|}{ Clinic Rotation } & \multicolumn{3}{|c|}{$\begin{array}{l}\text { Spaced Retrieval } \\
\text { Practice }\end{array}$} \\
\hline & & $\begin{array}{c}\text { Control } \\
n=13 \\
\end{array}$ & $\begin{array}{c}\text { EG1 } \\
n=10\end{array}$ & $\begin{array}{l}\mathrm{EG} 2 \\
n=7\end{array}$ & $\begin{array}{c}\text { Control } \\
n=8\end{array}$ & $\begin{array}{c}\mathrm{EG} 2 \\
n=10 \\
\end{array}$ & $\begin{array}{c}\text { Control } \\
n=21\end{array}$ & $\begin{array}{c}\text { EG1 } \\
n=10 \\
\end{array}$ & $\begin{array}{c}\text { EG2 } \\
n=17\end{array}$ \\
\hline 1 & None & \multicolumn{3}{|c|}{-} & \multicolumn{2}{|c|}{ Clinic 1} & - & - & - \\
\hline 2 & $\begin{array}{c}\text { Fluency/ } \\
\text { Voice Disorders } \\
\text { (CN X only) }\end{array}$ & \multicolumn{3}{|c|}{ Clinic 1} & \multicolumn{2}{|c|}{ Clinic 2} & - & - & $X$ \\
\hline 3 & $\begin{array}{c}\text { Neuromotor } \\
\text { Speech Disorders }\end{array}$ & \multicolumn{3}{|c|}{ Clinic 2} & \multicolumn{2}{|c|}{ Clinic 3} & - & $X$ & $X$ \\
\hline 4 & $\begin{array}{l}\text { Swallowing } \\
\text { Disorders }\end{array}$ & \multicolumn{3}{|c|}{ Clinic 3} & \multicolumn{2}{|c|}{ Clinic 4} & - & $X$ & $X$ \\
\hline 5 & None & \multirow{2}{*}{\multicolumn{3}{|c|}{$\begin{array}{l}\text { Clinic } 4 \\
\text { Clinic } 5\end{array}$}} & \multicolumn{2}{|c|}{ Clinic 5} & $X$ & $X$ & $X$ \\
\hline 6 & None & & & & \multicolumn{2}{|c|}{-} & - & - & - \\
\hline
\end{tabular}

$\mathbf{S}=$ Semester; Note: All students graduate in the same semester they complete clinic 5. 
Student participants comprised three groups consisting of a control group $(n=21)$ and two experimental groups $(n=27)$. Groups were based on the sequence of students' coursework upon enrollment in the master's program and length of the clinical program as determined by the timing of their clinical rotation (Table 1). The control group comprised 21 female students enrolled in the master's program prior to the implementation of the spaced retrieval practice protocol. The purpose of the control group was to serve as a comparison of standard instructional practices on retention of cranial nerve knowledge versus the use of spaced retrieval practice of varying frequencies. Experimental group 1 (EG1) comprised 10 female students and experimental group 2 (EG2) comprised 1 male and 16 female students.

Procedures. As part of the typical curriculum, students in the experimental and control groups received focused instruction on the specific cranial nerve(s) most relevant to the course subject. Learning activities, assignments, and assessments completed by all students were consistent with the established curriculum. At the beginning of each semester, students in the experimental groups participated in spaced retrieval practice by completing a self-developed matrix, Cranial Nerve Knowledge Assessment (Figure 1). The pen-and-paper assessment was presented as a 4x13 table with the following headings: 'Numeral and Name', 'Motor/Sensory/Both', 'What body part does it innervate?', and 'Function/What does it do?'. The students were oriented to matrix organization and instructed to complete the matrix to the best of their knowledge. Students in the control group only completed the Cranial Nerve Knowledge Assessment in the second semester of the second year. Thus, the control group was used to gauge how much knowledge students retained as a result of the typical curriculum instruction.

\section{Cranial Nerve Pre-Knowledge Assessment}

Identifier: (year of first enrollment 3-digit identifier) e.g. 2015201

Number of courses you received instruction on Cranial Nerves:

Answer the following questions to the best of your knowledge. This will not be calculated in your course grade. Scoring example provided in Bold.

\begin{tabular}{|l|l|l|l|}
\hline $\begin{array}{l}\text { Cranial Nerves } \\
\text { (Roman Numeral \& } \\
\text { Name) }\end{array}$ & $\begin{array}{l}\text { Motor } \\
\text { Sensory } \\
\text { Both }\end{array}$ & $\begin{array}{l}\text { What body part does it } \\
\text { innervate? }\end{array}$ & $\begin{array}{l}\text { Function } \\
\text { (i.e. what does it do?) }\end{array}$ \\
\hline $\begin{array}{l}\text { Olfactory } \\
\text { Quality score = 3 } \\
\text { (correct and } \\
\text { incomplete) }\end{array}$ & $\begin{array}{l}\text { No Answer } \\
\text { Quality =1 } \\
\text { (no answer) }\end{array}$ & $\begin{array}{l}\text { Eves } \\
\text { Quality = 2 } \\
\text { (incorrect) }\end{array}$ & $\begin{array}{l}\text { Sense of Smell } \\
\text { Quality =4 } \\
\text { (correct) }\end{array}$ \\
\hline & & & \\
\hline
\end{tabular}

Figure 1. Cranial Nerve Knowledge Assessment matrix distributed to students (scoring example was not provided to students).

After the students in the experimental groups completed the spaced retrieval practice activity, they received overview instruction on the 12 cranial nerves. To control for content of the overview instruction, the same PowerPoint presentation was used in the content courses: fluency, voice disorders, neuromotor speech disorders, and swallowing disorders. A traditional lecture format 
was used by each instructor to ensure consistency in instruction. Although the same instructor did not teach each content course, each instructor had experience teaching neuroanatomy as it related to their content area and were similar in terms of their teaching experience. The PowerPoint presentation covered the 12 cranial nerves, type, innervation, and function as it relates to speech and swallowing. Each slide outlined the primary motor and sensory function for a single cranial nerve accompanied by a simple illustration of the structure and/or function. The overview instruction provided in the PowerPoint presentation was supplemental to any instruction usually included in the curriculum. While students did not receive individual feedback on their performance on the Cranial Nerve Knowledge Assessment, they were given an opportunity to ask questions during the overview instruction.

Outcome Measure. Student performance on the Cranial Nerve Knowledge Assessment for each spaced retrieval practice was used as a measure of learning. The accuracy and quality of the student's recall for each element (name, type, body part, function) on the Cranial Nerve Knowledge Assessment relative to the content of the overview instruction was scored. Since the amount of information for each cranial nerve differed, accuracy is reported as the proportion of correct over total possible. A measure of the quality of the recalled information was scored using the following scale: 1) no answer; 2) incorrect; 3) correct and incomplete; 4) correct and complete. A quality scoring example is embedded within the Cranial Nerve Knowledge Assessment (Figure 1).

Analyses. This quasi-experimental study used both a repeated measures and between groups design where the control group was not randomly assigned. To compare performance between treatment groups, a multivariant analysis of variance (MANOVA) was used to determine if the number of semesters (i.e., none, three, four) students participated in spaced retrieval practice affected accuracy and completeness of recall for each dependent variable (i.e., name, body part, type, function of cranial nerves). A one-way independent repeated measures analysis of covariance (ANCOVA), where the control group served as the categorical covariate, was used to determine if the amount of spaced retrieval practice impacted the accuracy of cranial nerve knowledge recalled for students within each experimental group across the three (EG1) or four (EG2) semesters. A Wilcoxon-signed rank test was used to determine the effectiveness of spaced retrieval practice on the quality of recalled information for each dependent variable of each experimental group. A significance was considered at $p \leq .05$ for each statistic.

Inter-observer Agreement. Each Cranial Nerve Knowledge Assessment was completed in a faceto-face interaction by pen and paper monitored by the course instructor on record (i.e., one of the authors) for fidelity purposes. A graduate research assistant scored $100 \%$ of the assessments. A random sample of $25 \%$ from each group were scored by the second author for interrater agreement. Based on total number of assessments completed, 31 were analyzed for interrater agreement (6 from control group, 8 from EG1 and 17 from EG2). Comparisons were calculated by determining the number of agreements divided by the total number for an interrater agreement of $90 \%$.

\section{Results}

We used a quasi-experimental design to determine the effects of amount of spaced retrieval practice on cranial nerve knowledge for graduate SLP students. We measured four levels of cranial 
nerve knowledge (i.e., dependent variables: name, type, body part, and function) in graduate students who did not practice spaced retrieval (Centers for Disease Control and Prevention) and who practiced spaced retrieval across three (EG1) or four consecutive semesters (EG2) (i.e., independent variables: frequency of spaced retrieval practice - none, three semesters, four semesters). The four levels of cranial nerve knowledge were measured according to accuracy (e.g., percent accurate) and quality (e.g., no answer, incorrect, correct and incomplete, correct and complete).

Between Group Differences. To determine whether spaced retrieval practice resulted in more accurate responses compared to typical instruction, a MANOVA was conducted for each participant group (e.g., control, EG1, EG2) on accurate recall of cranial nerve knowledge for all four dependent variables. For the control, EG1, and EG2 groups, the scores for name, type, body part, and function were entered as the dependent variable. Using Pillai's trace, there was a significant effect of spaced retrieval practice (none, three semesters, four semesters) on the accuracy of recall of cranial nerve knowledge, $V=0.60, F(8,86)=4.544, p<.001$, partial eta squared $=.300$. The separate univariate ANOVAs indicated significant effects for recall of name, $F(2,45)=9.312, p<.001$, partial eta squared $=.293$; type, $F(2,45)=10.397, p<.001$, partial eta squared $=.316$; and function, $F(2,45)=17.608, p<.001$, partial eta squared $=.439$ of each cranial nerve. There were non-significant spaced retrieval practice effects on accurate recall for the body part each cranial nerve innervates, $F(2,45)=2.738, p=.075$, partial eta squared $=.109$.

Post-hoc comparisons using a Tukey HSD test indicated that the control group had significantly lower accuracy scores compared to EG1 and EG2 on recalling the name: EG1 $p<.001$; EG2 $p<$ .001 ; type: EG1 $p<.001$; EG2 $p<.001$; and function: EG1 $p<.001$; EG2 $p<.001$ of cranial nerves. However, EG1 and EG2 did not differ significantly from one another for any of the levels of knowledge (Figure 2).

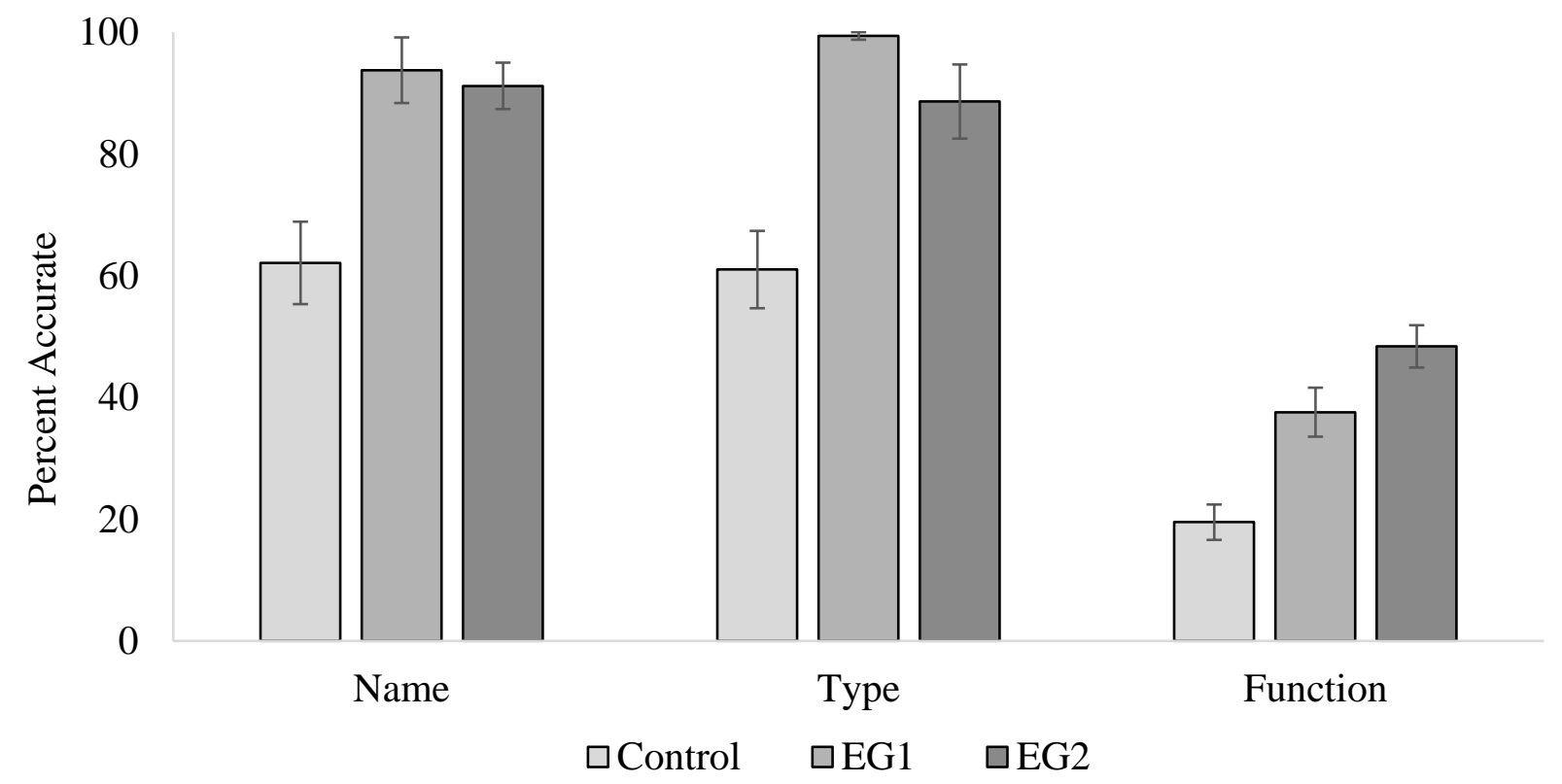

Figure 2. MANOVA showing between group differences on mean scores for accuracy of the three significant dependent variables 
To answer the second part of research question 1 regarding the quality of answers between groups a Kruskal-Wallis test was used. Kruskal-Wallis analysis allows comparison of more than one group on an ordinal variable for frequencies less than 5 . Results indicated that there was a significant main effect for recalling name, $H(2)=6.254, p=.04$; type, $H(2)=15.43, p<.001$; and function, $H(2)=13.754, p<.001$ of the cranial nerves. There was no significant effect when recalling body part, $H(2)=1.295, p=.52$.

Within Group Practice Effects. To answer the first part of research question 2, a one-way ANCOVA was conducted to determine the statistical significance between the number of semesters of spaced retrieval practice and accurate recall for each level of cranial nerve knowledge controlling for the retention expected from typical instruction. The control group was used as the covariate because it was hypothesized that the performance of the control group would be the minimum amount of retention expected for students receiving typical instruction.

For EG1, the main effect of number of semesters of spaced retrieval practice on accuracy of recall was not statistically significant for name, $F(1,2)=2.095, p=.26$, partial eta squared $=.067$; type, $F(1,2)=1.792, p=.28$, partial eta squared $=.058$; body part, $F(1,2)=1.187, p=.42$, partial eta squared $=.039$; and function $F(1,2)=3.748, p=.08$, partial eta squared $=.114$. When controlling for retention from typical instruction, there was a statistically significant difference between number of semesters and accurate recall for the name, $F(1,2)=5.024, p=.01$, partial eta squared $=.264$; type, $F(1,2)=4.793, p=.02$, partial eta squared $=.255$; body part $, F(1,2)=4.252, p=$ .03 , partial eta squared $=.128$; and function, $F(1,2)=9.727, p<.001$, partial eta squared $=.410$ of the cranial nerves. Pairwise comparisons between each semester of spaced retrieval practice identified a statistically significant difference in accurate recall for the name between the first and third semester of spaced retrieval practice $(p=.03)$ and function between the first and third $(p=$ $.00)$ and second and third $(p=.03)$ semester of spaced retrieval practice (Figure 3 ).

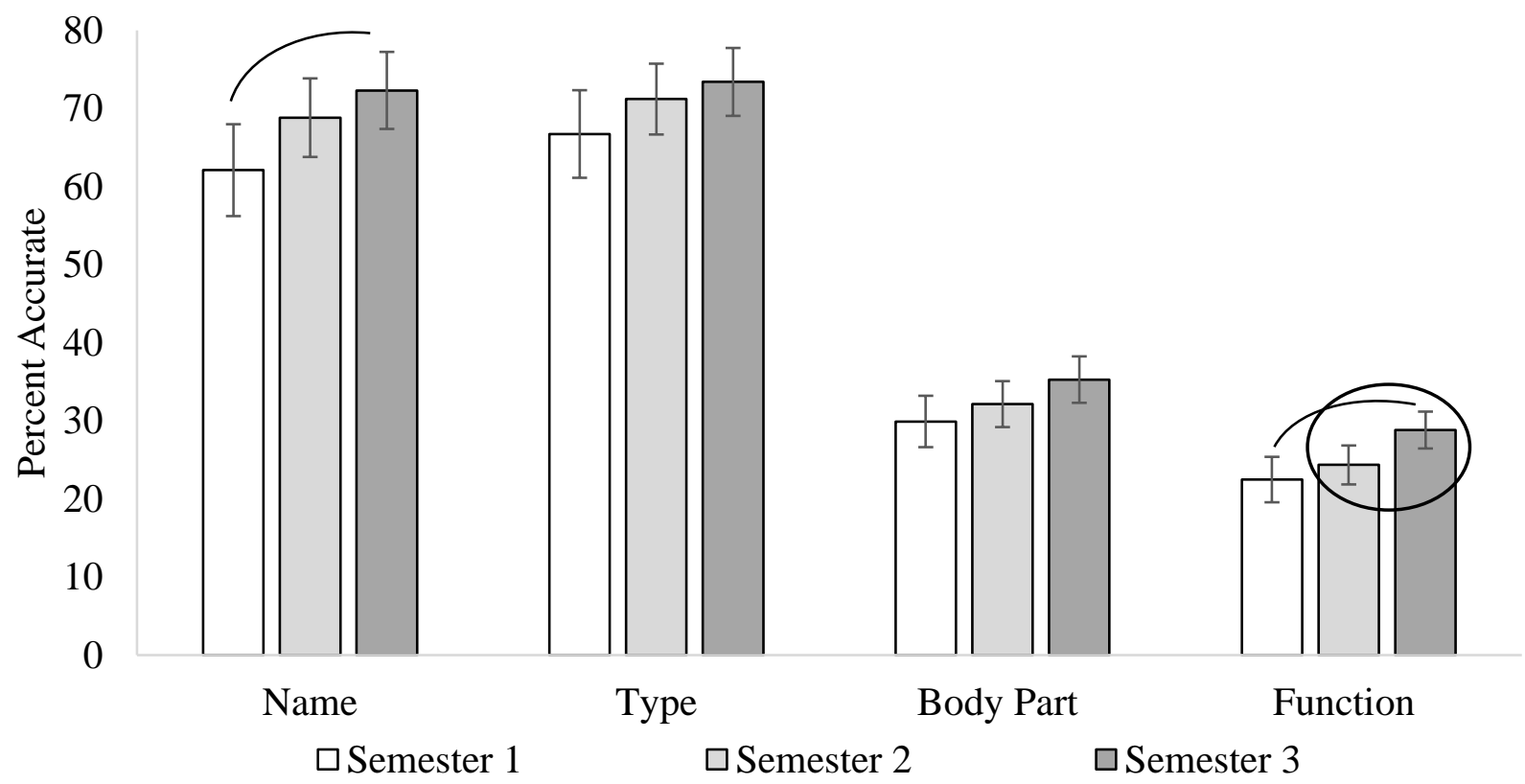


Figure 3. Pairwise comparisons of mean scores for graduate SLP students who participated in spaced retrieval practice across three semesters for each dependent variable. Statistically significant differences are marked.

For EG2, the main effect of number of semesters of spaced retrieval practice on accuracy of recall was statistically significant for name, $F(1,2)=8.225, p<.001$, partial eta squared = .186; type, $F(1,2)=4.370, p=.01$, partial eta squared $=.108$; body part, $F(1,2)=3.843, p=.03$, partial eta squared $=.096$; and function $F(1,2)=9.214, p<.001$, partial eta squared $=.204$. When controlling for retention from typical instruction, there was a statistically significant difference between number of semesters and accurate recall for the name, $F(1,3)=19.263, p<.001$, partial eta squared $=.349$; type, $F(1,3)=10.235, p<.001$, partial eta squared $=.221$; body part, $F(1,3)$ $=9.000, p<.001$, partial eta squared $=.200$; and function, $F(1,3)=21.580, p<.001$, partial eta squared $=.375$ of the cranial nerves. A pairwise comparison between each semester of spaced retrieval practice for EG2 determined there was a statistically significant difference for accurate recall of the name between semesters 1 and $3(p=.005), 1$ and $4(p<.001), 2$ and $3(p=.021), 2$ and $4(p<.001)$, and 3 and $4(p=.002)$; type, between semesters 1 and $3(p<.001), 1$ and $4(p=$ $.01), 2$ and $3(p<.001), 2$ and $4(p<.001)$; body part, between semesters 1 and $3(p<.001), 1$ and $4(p=.004), 2$ and $3(p<.001), 2$ and $4(p=.01)$; and function between semesters 1 and $3(p<$ $.003), 1$ and $4(p<.001), 2$ and $3(p<.001), 2$ and $4(p<.001)$, and 3 and $4(p=.004)$ (Figure 4$)$.

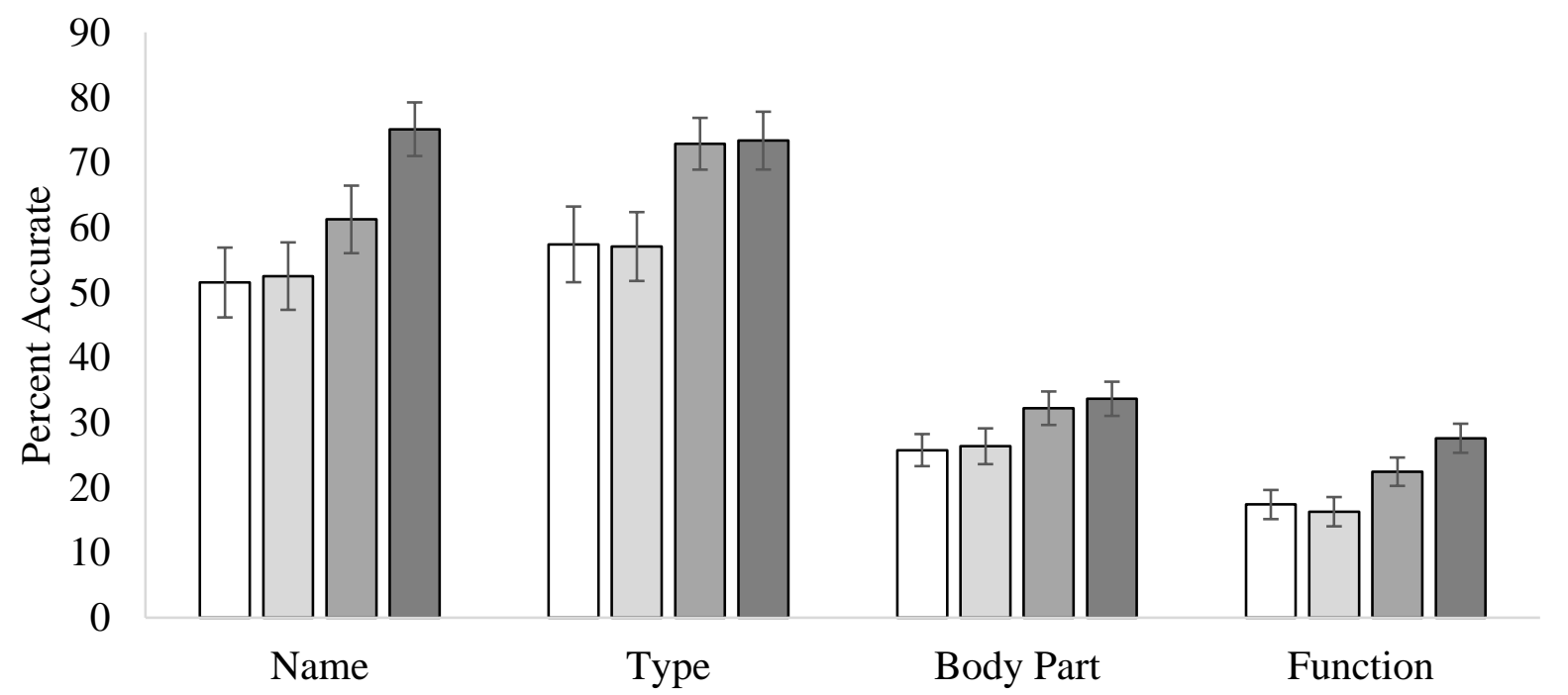

$\square$ Semester $1 \quad \square$ Semester $2 \quad \square$ Semester $3 \quad \square$ Semester 4

Figure 4. Pairwise comparisons of mean accuracy scores for graduate SLP students who participated in spaced retrieval practice across four semesters for each dependent variable.

To answer the second part of research question 2 regarding the difference in the quality of answers for each level of cranial nerve knowledge within EG1 and EG2, a Wilcoxon-signed rank test was performed to compare performance between the first and last spaced retrieval practice for the same students (Woolson, 2008). For EG1, improvement in the quality of answers was not statistically significant for name $(\mathrm{z}=-1.90, p=.09, r=-.60)$, type $(z=-.557, p=.75, r=-.18)$, body part $(z=$ $-1.51, p=.17, r=-.49)$, or function $(z=-1.56, p=.17, r=-.49)$. For EG2, improvement in the quality of answers was statistically significant for name $(z=-3.270, p<.001, r=-.79)$, type $(z=-$ 
2.799, $p=.004, r=-.68)$, body part $(z=-3.18, p<.001, r=-.77)$, and function $(z=-3.17, p<.001$, $r=-.77)$.

\section{Discussion}

There is scarce research in the discipline of SLP and pedagogy practice regarding retention of core knowledge, especially content specific information such as cranial nerve knowledge. The purpose of this study was to reduce the gap in the literature and extend SLP educators' knowledge to improve teaching practices using functional and empirically supported teaching strategies. Specifically, the questions posed were 1) do SLP graduate students who participate in spaced retrieval practice have better retention of cranial nerve knowledge (e.g., name, type, function, body part innervated) as measured by accuracy and quality of responses than students who did not participate in spaced retrieval practice?, and 2) does the accuracy and quality of cranial nerve knowledge (e.g., name, type, function, body part innervated) recalled depend on the number of semesters the graduate SLP students participated in spaced retrieval practice? The outcomes from this study confirm that long-term retention of cranial nerve knowledge is not maintained without purposefully practicing retrieval of cranial nerve content. The practice of retrieving specific cranial nerve information frequently across multiple semesters significantly affects long-term retention improving both the accuracy and quality of cranial nerve knowledge.

Between Group Differences. All graduate SLP students who participated in spaced retrieval practice improved significantly in accurately retaining the name, type, and function of each cranial nerve when compared to graduate SLP students who did not practice spaced retrieval. However, spaced retrieval practice did not improve accurate retention of the body part(s) each cranial nerve innervates. Likewise, the frequency of spaced retrieval practice improved the quality of knowledge retained by graduate SLP students. Graduate SLP students who practiced spaced retrieval over either three or four semesters retained more correct and complete information regarding the names, type, and function of cranial nerves compared to students who did not practice spaced retrieval. Graduate SLP students did not experience a benefit in regard to the quality of their answers when recalling the body part each cranial nerve innervates. There was no significant difference in the accuracy or quality of cranial nerve knowledge retained between students who completed three or four semesters of spaced retrieval practice. The outcomes from this study contribute to the existing evidence that spaced retrieval practice is a powerful learning strategy (Karpicke \& Roediger, 2007; Roediger \& Butler, 2011; Smith, Roediger, \& Karpicke, 2013) demonstrated across different content areas (Hopkins, Lyle, Hieb, \& Ralston, 2015; Middleton et al., 2016) and retrieval conditions (Pyc \& Rawson, 2009). These results reassure educators that infusing spaced retrieval practice into content-rich courses will have a positive impact on graduate SLP students' retention.

Within Group Practice Effects. This project also aimed to determine if the accuracy and quality of cranial nerve knowledge recalled differed significantly between each semester of spaced retrieval practice for each experimental group. When controlling for the accuracy of recall from typical instruction, both experimental groups significantly improved the accuracy of recall for all levels of cranial nerve knowledge. There was minimal difference in the accuracy of cranial nerve knowledge recalled between the first and second semester of spaced retrieval practice for both experimental groups. For EG1, there was a significant difference in accurate recall between the first and third semester for only name and function. For EG2, there was a significant difference in 
accurate recall for all levels of cranial nerve knowledge between the second and third semester and continued significant improvement from the third and fourth semester for name and function. Based on these results, the additional spaced retrieval practice had a positive impact on the accurate retention of cranial nerve knowledge for graduate SLP students. These results confirm that participating in spaced retrieval practice one time is inadequate for long-term retention and suggest that the initial retrieval practice may serve as a primer for learning with subsequent spaced retrieval practice solidifying the pathway of retrieval of learned information (Hauptmann \& Karni, 2002; Poldrack, Selco, Field, \& Cohen, 1999; Tulving, 1999).

The quality of the information retained improved significantly for all levels of cranial nerve knowledge only for the experimental group who participated in spaced retrieval practice across four consecutive semesters. These results provide additional evidence that spaced testing tasks produce large effects of learning (Weinstein et al., 2018). While direct individual feedback on performance was not provided to students, it is reasonable to suggest that the instruction provided immediately after spaced retrieval practice served as feedback for students to facilitate metacognitive monitoring, complete and correct levels of cranial nerve knowledge, and resolve uncertainty of any unsuccessful attempts (Butler et al., 2007; Carpenter et al., 2012; Rowland, 2014). A consideration for future research is to identify any benefits of spacing the instruction following the spaced retrieval practice (e.g., pre-test at the beginning of each semester, instruction provided 1 to 2 weeks later) to enhance long-term retention (Metcalfe et al., 2009; Smith \& Kimball, 2010).

Limitations. The small number of students in the group who participated in spaced retrieval practice across three consecutive semesters (EG1; $n=10)$ may not have been large enough to identify significance in the accuracy and quality of retained information for each level of knowledge in comparison to the experimental group who practiced spaced retrieval across four semesters $(\mathrm{EG} 2 ; n=17)$. Given this study was completed with a single cohort, although representative of a typical graduate student and normal distribution between groups, replication across multiple cohorts would contribute a broader understanding of the influence spaced retrieval practice has on long-term retention.

Similarly, expanding the investigation to distinguish the benefits of spaced retrieval practice in the absence of the repeated overview instruction may provide useful insights. In this study, overview instruction was always provided after the spaced retrieval activity and supplemental to the typical curriculum instruction. It would be beneficial to identify if the outcomes of spaced retrieval practice in the absence of the overview instruction are comparable to outcomes found in the current study. If true, spaced retrieval practice could be used as a low-stakes test with minimal interruption to the established curriculum to frequently revisit core knowledge.

Conclusions/Implications. The findings from this study provide evidence that using spaced retrieval practice in a graduate SLP curriculum is beneficial for long-term retention of core knowledge for cranial nerves. The accuracy and quality of cranial nerve knowledge retrieved was greatest in the students who practiced spaced retrieval across four consecutive semesters. Not only do the outcomes from this study contribute to the growing empirical evidence of spaced retrieval practice for long-term retention, they also provide a guideline of frequency for spaced retrieval practice effectiveness. SLP educators could facilitate and promote long-term retention of core 
curriculum content by introducing spaced retrieval practice as a component of instruction in courses where new learning is an extension of existing knowledge.

\section{References}

Agarwal, P. K., D'Antonio, L., Roediger, H. L., McDermott, K. B., \& McDaniel, M. A. (2014). Classroom-based programs of retrieval practice reduce middle school and high school students' test anxiety. Journal of Applied Research in Memory and Cognition, 3(3), 131139. doi:10.1016/j.jarmac.2014.07.002

Baturay, M., Yildirim, S., \& Daloglu, A. (2009). Effects of web-based spaced repetition on vocabulary retention of foreign langauge learners. Eurasian Journal of Education Research, 34, 17-36.

Brackenbury, T., Folkins, J. W., \& Ginsberg, S. M. (2014). Examining educational challenges in communication sciences and disorders from the perspectives of signature pedagogy and reflective practice. Contemporary Issues in Communication Sciences and Disorders, 41, 70-82. doi:1092-5171/14/4101-0070

Brush, J. A., \& Camp, B. J. (1998). Using spaced-retrieval as an intervention during speechlanguage therapy. Journal Clinical Gerontologist, 19(1), 51-64.

Butler, A. C., Karpicke, J. D., \& Roediger, H. L. (2007). The effect of type and timing of feedback on learning from multiple-choice tests. Journal of Experimental Psycholology: Applied, 13(4), 273-281. doi:10.1037/1076-898X.13.4.273

Butler, A. C., Karpicke, J. D., \& Roediger, H. L. (2008). Correcting a metacognitive error: Feedback increases retention of low-confidence correct responses. Journal of Experimental Psychololgy: Learning, Memory, and Cognition, 34(4), 918-928. doi:10.1037/02787393.34.4.918

Carnaby, G. (2016). Food for thought: Importance of a clinical exam/cranial nerve assessment. Perspectives of the ASHA Special Interest Groups (Dysphagia), 21, 143-149.

Carpenter, S. K. (2012). Testing enhances the transfer of learning. Current Directions in Psychological Science, 21(5), 279-283. doi:10.1177/0963721412452728

Carpenter, S. K., Cepeda, N. J., Rohrer, D., Kang, S. H. K., \& Pashler, H. (2012). Using spacing to enhance diverse forms of learning: Review of recent research and implications for instruction. Educational Psychology Review, 24(3), 369-378. doi:10.1007/s10648-0129205-Z

Carpenter, S. K., \& DeLosh, E. L. (2006). Impoverished cue support enhances subsequent retention: Support for the elaborative retrieval explanation of the testing effect. Memory \& Cognition, 34(2), 268-276.

Centers for Disease Control and Prevention. (2017, April 27, 2017). Traumatic brain injury \& concussion. Retrieved from https://www.cdc.gov/traumaticbraininjury/get_the_facts.html

Council of Clinical Certification in Audiology and Speech-Language Pathology of the American Speech-Language-Hearing Association. (2013). 2014 standards for the certification of clinical competence in speech-language pathology. Retrieved from http://www.asha.org/Certification/2014-Speech-Language-Pathology-CertificationStandards/.

Dalton, J. C., Klein, J., \& Botts, D. C. (2017). Bridging the divide with sotl: Connecting knowledge with best practice in communication disorders. Perspectives of the ASHA Special Interest Groups (SIG 10), 2(1), 14-24. 
Dickson, K. A., \& Stephens, B. W. (2015). It's all in the mime: Actions speak louder than words when teaching the cranial nerves. Anat Sci Educ, 8(6), 584-592. doi:10.1002/ase.1531

Dobson, J. L. (2013). Retrieval practice is an efficient method of enhancing the retention of anatomy and physiology information. Advances in Physiology Education, 37(2), 184-191. doi:10.1152/advan.00174.2012

Dudding, C. C., \& Nottingham, E. E. (2017). A national survey of simulation use in university programs in communication sciences and disorders. American Journal of SpeechLanguage Pathology, 27(1), 1-11. doi:10.1044/2017_AJSLP-17-0015

Dunlosky, J., Rawson, K. A., Marsh, E. J., Nathan, M. J., \& Willingham, D. T. (2013). Improving students' learning with effective learning techniques: Promising directions from cognitive and educational psychology. Psychological Science in the Public Interest, 14(1), 4-58. doi:10.1177/1529100612453266

Folkins, J. W. (2016). Are we asking the right questions about pedagogy in communication sciences and disorders? Contemporary Issues in Communication Sciences and Disorders, 43, 77-86. doi:1092-5171/16/4301-0077

Greene, R. L. (2008). Repetition and spacing effects. In J. H. Byrne (Ed.), Learning and memory: A comprehensive reference. (1st ed., Vol. 2, pp. 65-78). Oxford, England: Elsevier.

Grimaldi, P. J., \& Karpicke, J. D. (2012). When and why do retrieval attempts enhance subsequent encoding? Memory \& Cognition, 40(4), 505-513. doi:10.3758/s13421-011-0174-0

Halamish, V., \& Bjork, R. A. (2011). When does testing enhance retention? A distribution-based interpretation of retrieval as a memory modifier. Journal of Experimental Psychology: Learning, Memory, and Cognition, 37(4), 801-812. doi:10.1037/a0023219

Hauptmann, B., \& Karni, A. (2002). From primed to learn: The saturation of repetition priming and the induction of long-term memory. Cognitive Brain Research, 13(3), 313-322. doi:10.1016/S0926-6410(01)00124-0

Hopkins, R. F., Lyle, K. B., Hieb, J. L., \& Ralston, P. A. S. (2015). Spaced retrieval practice increases college students' short- and long-term retention of mathematics knowledge. Educational Psychology Review, 28(4), 853-873. doi:10.1007/s10648-015-9349-8

Huelser, B. J., \& Metcalfe, J. (2012). Making related errors facilitates learning, but learners do not know it. Memory \& Cognition, 40(4), 514-527. doi:10.3758/s13421-011-0167-z

Karpicke, J. D. (2017). Retrieval-based learning: A decade of progress. In J. H. Byrne (Ed.), Learning and memory: A comprehensive reference (2nd ed., Vol. 2, pp. 487-514). Oxford, England: Elsevier.

Karpicke, J. D., \& Bauernschmidt, A. (2011). Spaced retrieval: Absolute spacing enhances learning regardless of relative spacing. Journal of Experimental Psychology: Learning, Memory, and Cognition, 37(5), 1250-1257. doi:10.1037/a0023436

Karpicke, J. D., \& Roediger, H. L. (2007). Repeated retrieval during learning is the key to longterm retention. Journal of Memory and Language, 57(2), 151-162. doi:10.1016/j.jml.2006.09.004

Larsen, D. P. (2018). Planning education for long-term retention: The cognitive science and implementation of retrieval practice. Seminars in Neurology, 38(4), 449-456. doi:10.1055/s-0038-1666983

Logan, J. M., \& Balota, D. A. (2008). Expanded vs. Equal interval spaced retrieval practice: Exploring different schedules of spacing and retention interval in younger and older adults. Aging in Neuropsychology and Cognition, 15(3), 257-280. doi:10.1080/13825580701322171 
Logan, J. M., Castel, A. D., Haber, S., \& Viehman, E. J. (2012). Metacognition and the spacing effect: The role of repetition, feedback, and instruction on judgments of learning for massed and spaced rehearsal. Metacognition and Learning, 7(3), 175-195. doi:10.1007/s11409012-9090-3

Lone, M., McKenna, J. P., Cryan, J. F., Vagg, T., Toulouse, A., \& Downer, E. J. (2018). Evaluation of an animation tool developed to supplement dental student study of the cranial nerves. European Journal of Dental Education, 22(3), e427-e437. doi:10.1111/eje.12321

Martin, K., Bessell, N. J., \& Scholten, I. (2014). The perceived importance of anatomy and neuroanatomy in the practice of speech-language pathology. Anatomical Sciences Education, 7(1), 28-37. doi:10.1002/ase.1377

Metcalfe, J., Kornell, N., \& Finn, B. (2009). Delayed versus immediate feedback in children's and adults' vocabulary learning. Memory \& Cognition, 37(8), 1077-1087. doi:10.3758/MC.37.8.1077

Middleton, E. L., Schwartz, M. F., Rawson, K. A., Traut, H., \& Verkuilen, J. (2016). Towards a theory of learning for naming rehabilitation: Retrieval practice and spacing effects. $J$ Speech Lang Hear Res, 59(5), 1111-1122. doi:10.1044/2016_JSLHR-L-15-0303

Poldrack, R. A., Selco, S. L., Field, J. E., \& Cohen, N. J. (1999). The relationship between skill learning and repetition priming: Experimental and computational analyses. Journal of Experimental Psychology: Learning, Memory, and Cognition, 25(1), 208-235. doi:10.1037/0278-7393.25.1.208

Pyc, M. A., \& Rawson, K. A. (2009). Testing the retrieval effort hypothesis: Does greater difficulty correctly recalling information lead to higher levels of memory? Journal of Memory and Language, 60(4), 437-447. doi:10.1016/j.jml.2009.01.004

Richardson-Hatcher, A., Hazzard, M., \& Ramirez-Yanez, G. (2014). The cranial nerve skywalk: A 3d tutorial of cranial nerves in a virtual platform. Anatomical Sciences Education, 7(6), 469-478. doi:10.1002/ase. 1445

Roediger, H. L., \& Butler, A. C. (2011). The critical role of retrieval practice in long-term retention. Trends in Cognitive Sciences, 15(1), 20-27. doi:10.1016/j.tics.2010.09.003

Roediger, H. L., \& Karpicke, J. D. (2006). The power of testing memory: Basic research and implications for educational practice. Perspectives on Psychological Science, 1(3), 181210. doi:10.1111/j.1745-6916.2006.00012.x

Roediger, H. L., \& Pyc, M. A. (2012). Inexpensive techniques to improve education: Applying cognitive psychology to enhance educational practice. Journal of Applied Research in Memory and Cognition, 1(4), 242-248. doi:10.1016/j.jarmac.2012.09.002

Rowland, C. A. (2014). The effect of testing versus restudy on retention: A meta-analytic review of the testing effect. Psychological Bulletin, 140(6), 1432-1463. doi:10.1037/a0037559

Shea, C. H., Lai, Q., Black, C., \& Park, J. H. (2000). Spacing practice sessions across days benefits the learning of motor skills. Human Movement Science, 19(5), 737-760. doi:10.1016/S0167-9457(00)00021-X

Smith, M. A., Roediger, H. L., \& Karpicke, J. D. (2013). Covert retrieval practice benefits retention as much as overt retrieval practice. Journal of Experimental Psychology: Learning, Memory, and Cognition, 39(6), 1712-1725. doi:10.1037/a0033569

Smith, T. A., \& Kimball, D. R. (2010). Learning from feedback: Spacing and the delay-retention effect. J Exp Psychol Learn Mem Cogn, 36(1), 80-95. doi:10.1037/a0017407

Sobel, H. S., Cepeda, N. J., \& Kapler, I. V. (2011). Spacing effects in real-world classroom vocabulary learning. Applied Cognitive Psychology, 25(5), 763-767. doi:10.1002/acp.1747 
Soderstrom, N. C., \& Bjork, R. A. (2015). Learning versus performance: An integrative review. Perspectives on Psychological Science, 10(2), 176-199. doi:10.1177/1745691615569000

Strobel, J., \& van Barneveld, A. (2009). When is pbl more effective? A meta-synthesis of metaanalyses comparing pbl to conventional classrooms. Interdisciplinary Journal of ProblemBased Learning, 3(1), 44-58. doi:10.7771/1541-5015.1046

Tulving, E. (1999). Study of memory: Processes and systems. In J. K. Foster \& M. Jelicic (Eds.), Memory: Systems, process, or function? (pp. 11-30). New York, NY: Oxford University Press.

Vinney, L. A., \& Harvey, J. M. T. (2017). Bridging the gap: An integrated approach to facilitating foundational learning of neuroanatomy and neurophysiology in graduate-level speechlanguage pathology coursework. Teaching and Learning in Communication Sciences \& Disorders, 1(2). Retrieved from https://ir.library.illinoisstate.edu/tlcsd/vol1/iss2/1/

Weinstein, Y., Madan, C. R., \& Sumeracki, M. A. (2018). Teaching the science of learning. Cognitive Research: Principles and Implications, 3(1), 2. doi:10.1186/s41235-017-0087$\mathrm{y}$

Woolson, R. G. (2008). Wilcoxon signed-rank test. In J. M. L. S. R.B. D'Agostino (Ed.), Wiley encyclopedia of clinical trials. 